\title{
Impact of flower-dwelling crab spiders on plant-pollinator mutualisms
}

\author{
Rolf Brechbühl ${ }^{\mathrm{a}, \mathrm{b}, *}$, Christian Kropf ${ }^{\mathrm{c}}$, Sven Bacher ${ }^{\mathrm{a}, \mathrm{b}}$

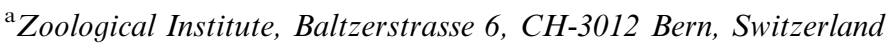 \\ ${ }^{\mathrm{b}}$ Department of Biology, Chemin du Musée 10, CH-1700 Fribourg, Switzerland \\ ${ }^{\mathrm{c}}$ Natural History Museum, Bernastrasse 15, CH-3005 Bern, Switzerland
}

\begin{abstract}
Indirect effects in interactions occur when a species influences a third species by modifying the behaviour of a second one. It has been suggested that indirect effects of crab spiders (Thomisidae) on pollinator behaviour can cascade down the food web and negatively affect plant fitness. However, it is poorly understood how different pollinator groups react to crab spiders and, thus, when a reduction in plant fitness is likely to occur. Using continuous video surveillance, we recorded the behaviour of pollinators on two flower species and the pollinators' responses to three crab spider treatments: inflorescences (1) with a pinned dried spider, (2) with a spider model made of paper, and (3) without spiders (control). We found that pollinators avoided inflorescences with dried spiders only on one plant species (Anthemis tinctoria). Pollinators showed no significant avoidance of paper spiders. Honeybees and bumblebees did not react to dried spiders, but solitary bees and syrphid flies showed a strong avoidance. Finally, we found no evidence that inflorescences with dried spiders suffered from a decrease in fitness in terms of a reduced seed set. We hypothesise that top-down effects of predators on plants via pollinators depend on the degree of specialisation of pollinators and their tendency to avoid spiders.
\end{abstract}

\section{Zusammenfassung}

Indirekte Effekte entstehen, wenn eine Art eine Dritte beeinflusst, indem sie das Verhalten einer zweiten Art modifiziert. Es wird vermutet, dass Bestäuber Pflanzen, auf denen Krabbenspinnen (Thomisidae) jagen, meiden und dass sich dies auf die Fitness der Pflanzen niederschlagen könnte, da diese weniger besucht würden. Allerdings ist bisher nicht bekannt, wie verschiedene Bestäubergruppen auf Spinnen reagieren und wann eine Fitnessreduktion der Pflanzen zu erwarten ist. Die Reaktion von Bestäubern auf (1) getrocknete Spinnen, (2) künstliche Papierspinnen und (3) Blüten ohne Spinnen (Kontrolle) wurde auf zwei verschiedenen Blütenarten mit Hilfe von kontinuierlicher Videoüberwachung untersucht. Die Resultate zeigen, dass die Bestäuber auf der einen Pflanzenart (Anthemis tinctoria) die getrockneten Spinnen mieden. Die Bestäuber zeigten keine signifikante Meidung bezüglich der Papierspinnen. Hummeln und Bienen reagierten nicht negativ auf die Spinnen, während solitäre Bienen und Schwebfliegen die Blüten mit getrockneten Spinnen stark mieden. Einen Einfluss auf die Fitness der Blüten hatte dies allerdings nicht, und es konnte kein Unterschied in der Anzahl gekeimter Samen zwischen Blüten mit getrockneten Spinnen und den Kontrollblüten

\footnotetext{
*Corresponding author at: Department of Biology, Chemin du Musée 10, CH-1700 Fribourg, Switzerland. Tel.: + 41 26300 8849; fax: + 41263009698.

E-mail address: rolf.brechbuehl@unifr.ch (R. Brechbühl).
} 
festgestellt werden. Wir stellen die Hypothese auf, dass “top-down"-Effekte auf Pflanzen durch Prädation auf Bestäuber vom Ausmass der Spezialisierung der einzelnen Bestäubergruppen und deren Tendenz Spinnen zu meiden, abhängen dürften.

Keywords: Indirect effects; Multitrophic interactions; Plant fitness; Predation; Xysticus

\section{Introduction}

The majority of flowering plants depend on animals for pollination (e.g. 90\% in Buchmann \& Nabhan 1996) and most of them are pollinated by insect pollinators (e.g. 67\% in Tepedino 1979; see also Abrahamson 1989; Faegri \& van der Pijl 1971). Thus, plant-pollinator mutualisms are presumably the most frequently studied mutualisms in ecology. However, little is known about disruptions of these mutualisms by flower-dwelling predators that prey on or deter pollinators (but see Dukas \& Morse 2005; Louda 1982; Muñoz \& Arroyo 2004; Romero \& Vasconcellos-Neto 2004; Suttle 2003). The presence of a predator can cascade down via its prey to the primary producers. These indirect top-down effects can have important consequences resulting in a reduced seed set in flowering plants (Suttle 2003). However, the conditions under which flower-dwelling predators are likely to have an influence on pollinators and in turn on plant fitness are still obscure. Most studies on pollinator deterrence by crab spiders have focused on social pollinators, such as many of the widespread bumblebees and honeybees (Dukas 2001; Heiling, Herberstein, \& Chittka 2003; Heiling, Cheng, \& Herberstein 2003; Heiling \& Herberstein 2004; Heiling, Chittka, Cheng, \& Herberstein 2005; Schmalhofer 2001). While social bees certainly are important in pollination ecology due to their dominance on many flower species, social pollinators may not be representative of the entire natural community of pollinators, because pollinator taxa differ in a variety of aspects (e.g. behaviour, size, sociality). Plant species greatly vary in their suite of pollinators, and there are many plants that are mainly pollinated by non-social species (Kormann 1988; Steffan-Dewenter 1998). Interactions between flower-dwelling predators and more species-rich nonsocial pollinator groups, such as solitary bees and syrphid flies, are sparsely studied (but see Schmalhofer 2001).

Crab spiders are known to ambush pollinators on flowers (Dukas 2001; Dukas \& Morse 2003; Romero \& Vasconcellos-Neto 2004; Schmalhofer 2001; Suttle 2003). They settle on inflorescences (Heiling \& Herberstein 2004; Morse 1979, 1981, 1983, 1986; Schmalhofer 2001; Théry \& Casas 2002) and wait motionless for their prey, mainly pollinating insects (Chittka 2001; Dukas \& Morse 2003; Fritz \& Morse 1985; Schmalhofer 2001). As direct observations in the field are inefficient and time consuming (Sunderland, Powell, \& Symondson 2005), we used continuous video surveillance to monitor large number of flower-visiting insects. In this study we focus on how insect pollinators react to dried specimens of flower-dwelling crab spiders and two-dimensional paper spiders. Furthermore, we also investigated if the disturbance of the plant-pollinator mutualism by predators has a negative effect on the pollination success of flowers.

\section{Materials and methods}

\section{Study area and species}

All experiments were conducted in the garden of the Zoological Institute in Bern (Switzerland) from June to August in 2005. Seedlings of two native, non-selfing plant species (Centaurea scabiosa, and Anthemis tinctoria [Asteraceae]) were planted in plastic pots (161) in the spring of 2005. We used 20 pots, each containing both plant species. Pots were distributed uniformly over the garden with a minimum distance of three meters between them. The pots represented the only flowering patches in the experimental area, as the vegetation between them was cut regularly.

Xysticus cristatus and X. kochii (Thomisidae) females were collected by sweep-netting on wildflower areas around Bern. Both crab spider species are very similar in their morphology and ecology, and we did not discriminate between them. These Xysticus species feed on a variety of prey species. When hunting on inflorescences they mainly prey on flying pollinators ranging in size from small syrphid flies to bumblebees (Nyffeler \& Breene 1990; personal observation). To make crab spider dummies, we killed spiders by freezing, then pinned and dried them on polystyrene with legs spread like a hunting spider (see Appendix A: Fig. 1A).

\section{Spider experiment}

We recorded the response of pollinators towards three different crab spider treatments on inflorescences of two plant species in a complete factorial design. The spider treatments consisted of (1) dried spider specimen (see 

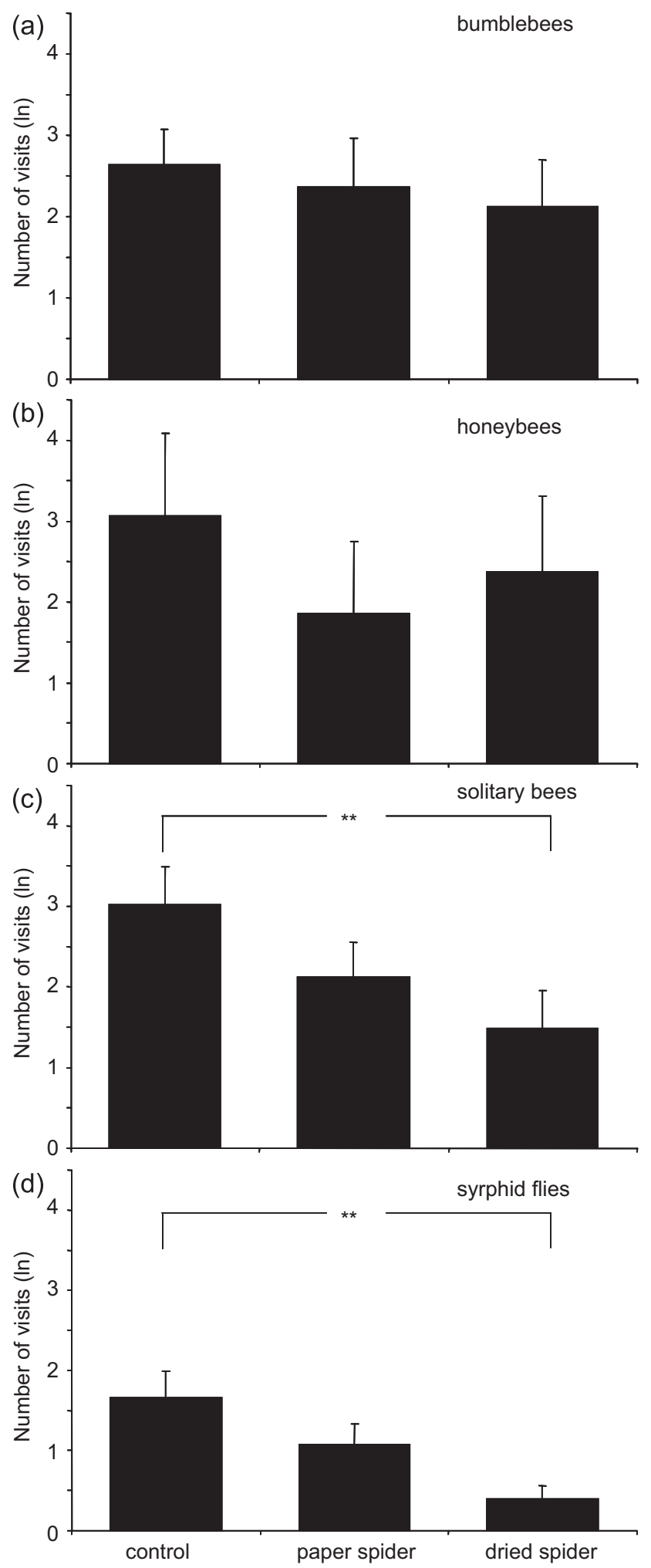

Fig. 1. Total number of pollinator visits (mean $+\mathrm{SE}$; lntransformed) according to spider treatment (control, paper spider, dried spider): (a) bumblebees (only on C. scabiosa), (b) honeybees (only on C. scabiosa), (c) solitary bees, and (d) syrphid flies. Significances between treatments: ${ }^{* *} p<0.01$, see Table 2. above) fixed with an insect pin (size 2) on top of the inflorescences in a position typical of flower-dwelling crab spiders, (2) two-dimensional brown paper spiders (see Appendix A: Fig. 1B) of similar size and shape made of brown paper (Buntpapierfabrik Ludwig Bähr GmbH \& Co., tinted drawing paper $130 \mathrm{~g} / \mathrm{m}^{2}$, colour: 72 mid-brown) fixed with an insect pin on top of inflorescences and (3) inflorescences without spiders (control). Hence, we had six treatment combinations (three spider treatments $\times$ two flower species). Each treatment combination was repeated six times, resulting in altogether 36 replicates. We monitored pollinator visits to individual inflorescences with nine wireless digital video surveillance cameras (Axis 206W). Owing to the limited number of cameras, we conducted the entire experiment in four temporal blocks of three days each, during which we observed flower visitation in nine treatment combinations simultaneously. At the beginning of each temporal block, three equally-sized inflorescences of the same plant species from three of the twenty pots, chosen at random, were assigned to the three different spider treatments (control, paper spider and dried spider specimen). In each temporal block, we observed one replicate of all spider treatments in one flower species and two replicates of each spider treatment in the other plant species, alternating this pattern in the next block.

The cameras sent the pictures continuously via two wireless access points (Enterasys, RoamAbout, RBT3K) to the internet from which they were accessed by a personal computer running the surveillance software "go1984" (logiware, version 3.0 pro). All visits by flower-visiting insects and the time (s) spent on the inflorescences were recorded. Flower visitors were assigned to one of five groups (bumblebees, honeybees, solitary bees, syrphid flies or others). In addition, we measured the height of each inflorescence above the soil surface $(\mathrm{cm})$ and its diameter $(\mathrm{cm})$. The surface area $\left(\mathrm{cm}^{2}\right)$ of spider specimen and paper spiders was determined from digital images with the software IMAQ Vision Builder 6 (National Instruments).

Ants were excluded from inflorescences by sticky insect glue (Tanglefoot) around the shoots, as they otherwise attacked the dried spiders.

\section{Pollination success}

In order to prevent pollination before and after the recordings, we covered those flower buds that we planned to use for the experiments with gauze bags until flowering started. Bags were removed during the experimental days and immediately replaced afterwards. Thus we were able to evaluate the effect of the different spider treatments on flower pollination success. Seven days after the spider experiment, when inflorescences 
started wilting, we removed the gauze bags and cut the experimental inflorescences. In the laboratory, the petioles were placed in glass cylinders filled with water until seed germination. We counted the mature seeds from each inflorescence and placed them in Petri dishes ( $9 \mathrm{~cm}$ diameter) on wet cotton until seeds germinated. The number of seeds that germinated was determined.

\section{Statistical analysis}

We tested for preferences of the different pollinator groups with a linear mixed effects model (function lme in the statistical software $R$ ) fitted by maximum likelihood (ML). The number of visits, the duration of visits on the inflorescences (both ln-transformed), and the number of seeds germinated (sqrt-transformed) were used as dependent variables. The flower species and the spider treatment were fixed factors (including their interaction), while inflorescence height, diameter of the inflorescences and spider surface area were covariates. The temporal block was included as a random factor. We used a stepwise procedure to obtain minimum adequate models by removing variables that did not improve the fit of the model (tested by Akaikes Information Criterion AIC). All calculations were done in the statistical software " $\mathrm{R}$ " (version 2.6.0; R Development Core Team 2007).

\section{Results}

During our experiment, we recorded a total of 2838 insects visiting the observed inflorescences. The most frequent visitors were honeybees and solitary bees, each group with over 1000 visiting events (Table 1). Centaurea scabiosa was visited four times more often than $A$. tinctoria and was clearly preferred by pollinators, with bumblebees and honeybees being the most important visitors of C. scabiosa (Table 1). As bumblebees never visited $A$. tinctoria and honeybees did so only rarely, we analysed the data of these two groups for C. scabiosa only (see Table 2). Solitary bees as well as syrphid flies did not show any preference for one of the

Table 1. Total number of visits by five pollinator groups to C. scabiosa and A. tinctoria inflorescences.

\begin{tabular}{lccc}
\hline & Total visits & C. scabiosa & A. tinctoria \\
\hline Bumblebees & 359 & 359 & 0 \\
Honeybees & 1179 & 1159 & 20 \\
Solitary bees & 1037 & 626 & 411 \\
Syrphid flies & 140 & 72 & 68 \\
Others & 123 & 78 & 45 \\
Total & 2838 & 2294 & 544 \\
\hline
\end{tabular}

two flower species. These two pollinator groups were the most frequent visitors on A. tinctoria (Table 1).

\section{Spider experiment}

Pollinator visits generally decreased when dried spider specimens were present on inflorescences (Table 2). However, there were remarkable differences among pollinator groups. Bumblebees and honeybees did not react significantly to the spider treatments (Table 2; Fig. $1 \mathrm{a}$ and $\mathrm{b}$ ). By contrast, solitary bees and syrphid flies avoided inflorescences harbouring dried spider specimens compared to controls (Fig. 1c and d). Inflorescences with a paper spider occupied an intermediate position between the other two treatments, but were not significantly different from either (Table 2; Fig. 1c and d). Furthermore, there was a trend over all pollinators to show different avoidance behaviour towards the spiders on the different flower species, although this was not quite significant (interaction: flower species $\times$ dried spiders, lme: $t=1.98, p=0.059$ ); while on A. tinctoria a strong reaction to the spider treatments was observed, pollinators showed hardly any reaction on $C$. scabiosa (Fig. 2). However, this interaction was due to the preference for inflorescences of C. scabiosa of honeybees and bumblebees, which did not show any reaction to spider specimen. Solitary bees and syrphid flies, the groups that avoided spider specimens, did not react differently on different flower species (Table 2).

Apart from treatment effects, flower height and spider size remained in some of the minimum adequate models, but never explained significant parts of the variation (Table 2). The analysis of the length of time pollinators spent on inflorescences yielded results similar to those obtained for the number of visits; if spiders reduced the number of pollinator visits to inflorescences the average length of pollinator visits decreased likewise. The lme models for visit duration are given in Appendix A: Table 1.

\section{Pollination success}

Neither spider treatments nor any of the co-variates showed a significant influence on the pollination success of the inflorescences (Fig. 3). Only flower species remained in the minimum adequate model after stepwise reduction; more seeds germinated from $A$. tinctoria inflorescences than from $C$. scabiosa inflorescences $(A$. tinctoria: $5.3 \pm 0.5 ;$ C. scabiosa: $3.7 \pm 0.5 ;$ mean $\pm \mathrm{SE}$, sqrt-transformed; lme: $t=-2.08, p=0.04)$. It should be noted that the treatment of fixing dried spiders (or paper spiders) to inflorescences, thereby preventing pollinators from access to part of the inflorescences, did not result in a significantly reduced seed set in these 
Table 2. Minimum adequate linear mixed effects models of the reaction pollinators (number of visits) to flower species, spider treatments (paper spiders and spider specimens were compared to the control) and covariates.

\begin{tabular}{|c|c|c|c|c|c|c|c|c|c|c|}
\hline & \multicolumn{2}{|c|}{ All pollinators } & \multicolumn{2}{|c|}{ Bumblebees } & \multicolumn{2}{|c|}{ Honeybees } & \multicolumn{2}{|c|}{ Solitary bees } & \multicolumn{2}{|c|}{ Syrphid flies } \\
\hline & $t$-value & $p$ & $t$-value & $p$ & $t$-value & $p$ & $t$-value & $p$ & $t$-value & $p$ \\
\hline (Intercept) & 7.07 & $<0.001$ & - & - & 3.15 & 0.008 & 2.07 & 0.048 & 6.46 & $<0.001$ \\
\hline Flower species & 1.41 & 0.171 & NA & NA & NA & NA & - & - & - & - \\
\hline Paper spider & -1.74 & 0.094 & - & - & - & - & -1.49 & 0.146 & -1.61 & 0.118 \\
\hline Dried spider & -3.07 & 0.005 & - & - & - & - & -2.76 & 0.009 & -3.47 & 0.002 \\
\hline Flower species $\times$ paper spider & 0.34 & 0.735 & - & - & - & - & - & - & - & - \\
\hline Flower species $\times$ dried spider & 1.98 & 0.059 & - & - & - & - & - & - & - & - \\
\hline Height & - & - & - & - & - & - & 1.70 & 0.100 & - & - \\
\hline Spider size & 1.35 & 0.190 & - & - & -1.46 & 0.169 & - & - & - & - \\
\hline
\end{tabular}

NA: not applicable, i.e. data from C. scabiosa only; -: variables not included in the minimum adequate model. Diameter of inflorescences was never included in the minimum adequate model.

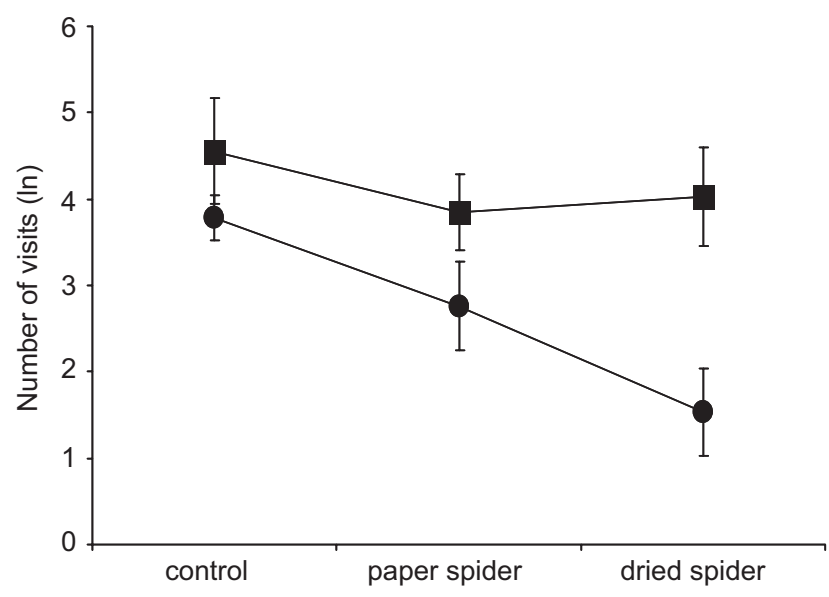

Fig. 2. Total number of pollinator visits (mean $\pm \mathrm{SE}$; lntransformed) on C. scabiosa (squares) and on $A$. tinctoria (circles) for three experimental treatments (control, paper spider, dried spider).

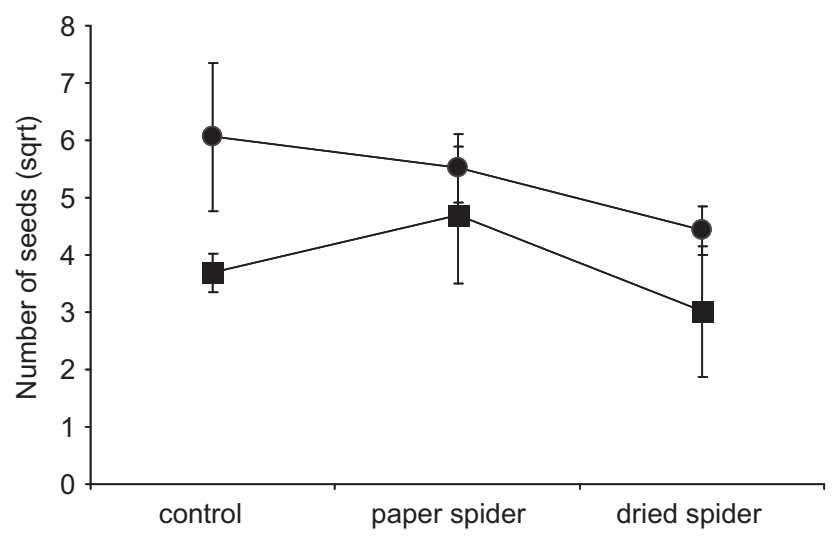

Fig. 3. Total number of seeds germinated (mean \pm SE; sqrttransformed) per C. scabiosa (squares) and A. tinctoria inflorescence (circles) in relation to spider treatment (control, paper spider, dried spider). non-selfing flowers (Marsden-Jones \& Turrill 1954, www.biolflor.de).

\section{Discussion}

The hypothesis that pollinators are deterred by the presence of crab spiders was only partially supported. Some pollinator groups did not react to the presence of spiders at all (bumblebees, honeybees), while other groups (solitary bees, syrphid flies) avoided dried spiders. It is therefore not straightforward to extrapolate behaviour from one pollinator group to the whole range of pollinators. Reasons for the difference in behaviour may lie in the different sizes of the pollinator groups (Dukas \& Morse 2003, 2005); the generally smaller solitary bees and syrphid flies showed a greater tendency to avoid crab spiders than the larger bumblebees and honeybees, which may be better protected from predation by their size alone. It may also be noteworthy that the pollinators that did not react to crab spiders in our study were social in contrast to those that avoided spiders. In social insects, the death of a worker only marginally reduces its fitness (Hamilton's rule, Clark \& Dukas 1994). Therefore, there may be less evolutionary pressure in social insects to a priori develop an avoidance reaction. However, in our study the effects of size and sociality were confounded with taxonomy and thus cannot be discriminated.

In contrast to our findings, some studies showed antipredator behaviour of honeybees and/or bumblebee species to crab spiders (Dukas 2001; Dukas \& Morse 2003; Reader, Higginson, Barnard, Gilbert \& The Behavioural Ecology Field Course 2006; Robertson \& Kelmash Maguire 2005). One reason for this discrepancy could lie in the fact that we were using dead spider specimens, while the other studies were done with live spiders. Honeybees and bumblebees may react stronger 
to movement (e.g. when the spider approaches the pollinator before the attack) than to visual cues. Furthermore, it should be noted that the spiders used in the above mentioned studies usually belonged to crab spider species that are thought to be cryptic (adaptation of body colour to colour of inflorescences, e.g. in the genera Misumena and Thomisus; see Chittka 2001; Heiling, Herberstein, \& Chittka 2003; Heiling, Cheng, \& Herberstein 2003; Théry \& Casas 2002). By contrast, our brown Xysticus spider specimens and the brown paper spiders (paper colour was chosen to visually match most closely the colour of the dried spider specimens) were very conspicuous on inflorescences. Such differences in spider colour may explain the different reactions of bumblebees and honeybees in our experiments compared to previous work.

We found no indications that crab spiders are costly for plants in our system. There was only a comparatively low and non-significant average reduction in germinated A. tinctoria seeds (27.0\% reduction, Fig. 3$)$ compared to the much stronger avoidance behaviour of solitary bees and syrphid flies, who were responsible for $88 \%$ of all visits on these inflorescences (59.4\% reduction, Fig. 2). Thus, the impacts of reduced flower visitation rates on the plant-pollinator mutualism are highly variable and also buffered, and may not always translate into biologically relevant fitness reductions in plants. On $C$. scabiosa, the major pollinator groups (bumblebees and honeybees, responsible for $66 \%$ of all visits) were not deterred by crab spiders and consequently there was no indication of an effect on seed set (Fig. 3). These findings are in line with the studies by Dukas and Morse (2003). In their system, honeybees and bumblebees were also the major pollinators; while honeybees showed reduced visitation frequencies on flowers harbouring spiders, bumblebees were not deterred by the predators. In contrast, Suttle (2003) found that plants with flowerdwelling crab spiders Misumenops schlingeri were visited less frequently $(37.7 \%$ reduction in visits) and for shorter durations, leading to significantly reduced seed set (although only by $2-17 \%$ ) in Leucanthemum vulgare. However, the opposite, namely that plants can also profit from harbouring a spider, has also been shown (Louda 1982; Romero \& Vasconcellos-Neto 2004); spiders protected the plants from herbivores resulting in increased seed set. Thus, the influence of flowerdwelling predators on the plant-pollinator mutualism depends on the predator, the potential prey and the plant taxon. Although the effects found so far are mixed, it appears that the largest reductions in seed set due to spiders hunting on flowers can be expected in plant-pollinator systems where the pollinator guild is composed of species that all strongly avoid spiders. Plants visited by a large variety of different pollinators will likely receive enough visits by pollinators insensitive to the presence of spiders to show great reductions in seed set. It follows that plant species with a narrow spectrum of specialised pollinators should be more prone to fitness reductions due to crab spiders. However, more data in different plant-pollinator systems are needed to verify this hypothesis.

In conclusion, we clearly demonstrated that pollinators reacted differently to the presence of crab spiders and that the effects can differ between plant species. Thus, any meaningful generalisation of the effect of crab spiders must take pollinator and plant identity into account (see Dukas \& Morse 2003; Reader et al. 2006). Furthermore, a significant reduction in pollinator visitation frequency does not necessarily lead to a significant fitness reduction in the plant. We hypothesise that top-down effects of predators on plants via pollinators depend on the degree of specialisation of pollinators and their tendency to avoid spiders.

\section{Acknowledgements}

We thank Eduard Jutzi and Anna Siegenthaler for assistance in technical matters and Jérôme Casas and Jérémy Défrize (both University of Tours, France), four anonymous reviewers and Klaus Hövemeyer for valuable comments on previous versions. This study was funded by the National Centre of Competence in Research (NCCR) Plant Survival, a research programme of the Swiss National Science Foundation.

\section{References}

Abrahamson, W. G. (1989). Plant-animal interactions. New York: McGraw Hill Book Company.

Buchmann, S. L., \& Nabhan, G. P. (1996). The forgotten pollinators. Washington DC: Island Press.

Chittka, L. (2001). Camouflage of predatory crab spiders on flowers and the colour perception of bees. Entomolgia Generalis, 25, 181-187.

Clark, C. W., \& Dukas, R. (1994). Foraging under predation hazard: an advantage of sociality. American Naturalist, 144, 542-548.

Dukas, R. (2001). Effects of perceived danger on flower choice by bees. Ecology Letters, 4, 327-333.

Dukas, R., \& Morse, D. H. (2003). Crab spiders affect flower visitation by bees. Oikos, 101, 157-163. 
Dukas, R., \& Morse, D. H. (2005). Crab spiders show mixed effects on flower visiting bees and no effect on plant fitness. Ecoscience, 12, 244-247.

Faegri, K., \& van der Pijl, L. (1971). The principles of pollination ecology. Oxford: Pergamon Press.

Fritz, R. S., \& Morse, D. H. (1985). Reproductive success and foraging of the crab spider Misumena vatia. Oecologia, 65 , 194-200.

Heiling, A. M., Herberstein, M. E., \& Chittka, L. (2003). Crab-spiders manipulate flower signals. Nature, 421, 334.

Heiling, A. M., Cheng, K., \& Herberstein, E. (2003). Exploitation of floral signals by crab spiders (Thomisus spectabilis, Thomisidae). Behavioral Ecology, 15(2), 321-326.

Heiling, A. M., \& Herberstein, M. E. (2004). Floral quality signals lure pollinators and their predators. Annual Zoological Fennici, 41, 421-428.

Heiling, A. M., Chittka, L., Cheng, K., \& Herberstein, M. E. (2005). Colouration in crab spiders: substrate choice and prey attraction. The Journal of Experimental Biology, 208, 1785-1792.

Kormann, K. (1988). Schwebfliegen Mitteleuropas. Landsberg/ München: Ecomed Verlagsgesellschaft mbH.

Louda, S. M. (1982). Inflorescence spiders: A cost/benefit analysis for the host plant, Haplopappus venetus blake (Asteraceae). Oecologia, 55, 185-191.

Marsden-Jones, E. M., \& Turrill, W. B. (1954). British knapweeds. London: Ray Society.

Morse, D. H. (1979). Prey capture by the crab spider Misumena calycina (Araneae: Thomisidae). Oecologia, 39, 309-319.

Morse, D. H. (1981). Prey capture by the crab spider Misumena vatia (Clerck) (Thomisidae) on three common native flowers. American Midland Naturalist, 105, 358-367.

Morse, D. H. (1983). Foraging patterns and time budgets of the crab spiders Xysticus emertoni Keyserling and Misumena vatia (Clerck) (Araneae: Thomisidae) on flowers. Journal of Arachnology, 11, 87-94.

Morse, D. H. (1986). Foraging behaviour of crab spiders (Misumena vatia) hunting on inflorescences of different quality. American Midland Naturalist, 116, 341-347.
Muñoz, A. A., \& Arroyo, A. T. K. (2004). Negative impacts of a vertebrate predator on insect pollinator visitation and seed output in Chuquiraga oppositifolia, a high Andean shrub. Oecologia, 138, 66-73.

Nyffeler, M., \& Breene, G. (1990). Spiders associated with selected European hay meadows, and the effects of habitat disturbance, with the predation ecology of the crab spiders, Xysticus spp. (Araneae, Thomisidae). Journal of Applied Entomology, 110, 149-159.

$\mathrm{R}$ Development Core Team (2007). R: A language and environment for statistical computing. Vienna, Austria: R Foundation for Statistical Computing.

Reader, T., Higginson, A. D., Barnard, C. J., Gilbert, F. S., \& The Behavioural Ecology Field Course (2006). The effects of predation risk from crab spiders on bee foraging behaviour. Behavioral Ecology, 17, 933-939.

Robertson, I. C., \& Kelmash Maguire, D. (2005). Crab spiders deter insect visitations to slickspot peppergrass flowers. Oikos, 109, 577-582.

Romero, G. Q., \& Vasconcellos-Neto, J. (2004). Beneficial effects of flower-dwelling predators on their host plant. Ecology, 85, 446-457.

Schmalhofer, V. R. (2001). Tritrophic interactions in a pollination system: Impacts of species composition and size of flower patches on the hunting success of a flowerdwelling spider. Oecologia, 129, 292-303.

Steffan-Dewenter, I. (1998). Wilbienen in der Agrarlandschaft: Habitatwahl, Sukzession, Bestäubungsleistung und Konkurrenz durch Honigbienen. Verlag Agrarökolgie: Agrarökologie Band 27.

Sunderland, K. D., Powell, W., \& Symondson, W. O. C. (2005). Populations and communities. In M. A. Jervis (Ed.), Insects as natural enemies (pp. 299-434). Berlin, Heidelberg, New York: Springer.

Suttle, K. B. (2003). Pollinators as mediators of top-down effects on plants. Ecology Letters, 6, 688-694.

Tepedino, V. J. (1979). The importance of bees and other insect pollinators in maintaining floral species composition. Great Basin Naturalist Memoirs, 3, 139-150.

Théry, M., \& Casas, J. (2002). Predator and prey views of spider camouflage. Nature, 415, 133. 